\title{
Survivin and Programmed Death Ligand-1 as Possible Players in the Pathogenesis of Ulcerative Colitis: An Immunohistochemical Study
}

\author{
Reham Shehab El Nemr Esmail ${ }^{1 *}$, Eman Hassan Abdelbary ${ }^{2}$ \\ ${ }^{1}$ Pathology Department, Faculty of Medicine, El-Fayoum University, Egypt; ${ }^{2}$ Pathology Department, Faculty of Medicine, \\ Zagazig University, Egypt
}

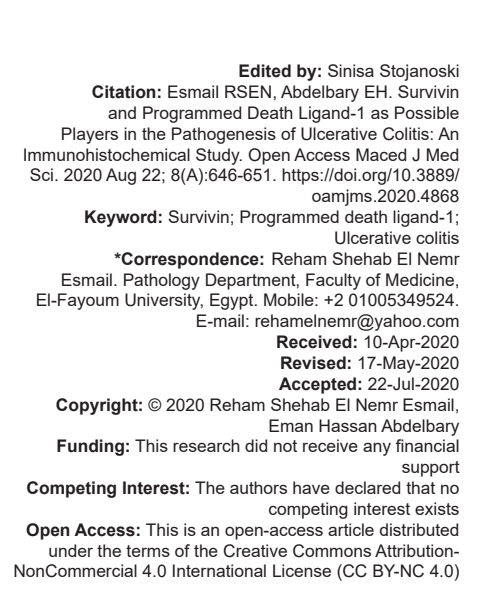

Abstract

BACKGROUND: Ulcerative colitis (UC) is a relapsing chronic inflammatory disorder, with many catastrophic complications. The pathogenesis of UC is not yet well understood. Exploring the exact immunologic pathogenesis of UC may eventually offer new therapeutic options.

AIM OF THE WORK: In this study, we proposed that survivin and programmed death ligand (PDL1) may have roles in the pathogenesis of UC.

MATERIALS AND METHODS: The study examined the immunohistochemical expression of both markers in the colonic epithelial cells and lamina propria in 43 cases of UC and 43 cases of non-specific chronic colitis (noninflammatory bowel disease colitis).

RESULTS: The results uncovered that both survivin and PDL1 expression were significantly expressed in the colonic lamina propria cells in UC cases in comparison to colitis cases $(p<0.001)$. On the other hand, the expression of PDL1 was shown to be lost in the colonic mucosal cells in UC cases when compared to cases of the control group $(p<0.05)$.

CONCLUSION: The study, therefore, concluded that both survivin and PDL1 may play an important role in the UC pathogenesis and hence may be a novel interest in new therapeutic trends.

\section{Introduction}

Ulcerative colitis (UC) is a chronic relapsing inflammatory bowel disease (IBD) that diffusely involves various parts of the colon, without skip lesions [1].

UC is usually presented by bloody diarrhea, rectal tenesmus, and abdominal pain. Colonoscopic examination is the fundamental diagnostic tool, as well, it assesses the disease activity, which guides the management strategy, and is the basic method for patient follow-up [1].

During disease activity, the affected areas of colonic mucosa show ulcers, exudates, fragile mucosa, and bleeding. The symptoms are greatly controlled by drugs which induces remissions. However, all the symptoms and signs of activity will eventually recur easily in the following exacerbation attacks [2].

The etiopathogenesis of UC is not yet clear and not until now fully understood; genetic and epigenetic factors are supposed to play a role [3]. Abnormal altered response of the mucosal immune cells to normally existent gut flora in genetically susceptible individuals is the most believed theory, the event that leads to increase many inflammatory chemical mediators, create a sustained state of oxidative stress, establish chronic inflammation, and disturb the colonic bacterial profile [4].

Many inflammatory cells are implicated in such process, with most of the studies strongly suggest a prominent role of $\mathrm{T}$ helper lymphocyte family including; CD 4+ helper cells types 1 and 2 (Th1 and Th2), CD4+ cells which produce interleukin-17 (Th17), and regulatory $\mathrm{T}$ cells (Treg) [5].

It was shown that the abnormal immune response to the gut flora seen in $U C$ is accompanied by prompt increase in mucosal T cells, mainly Th1 and Th2 subsets, dysregulation of their responses, and faulty $T$ cell inactivation that results in self- intolerance and autoimmune process development, however, to the moment, the mechanism underlying these events is not fully explored.

Survivin is a well-known apoptosis inhibitor, which modulate its antiapoptotic activity through direct inhibition of cytoplasmic caspase [6]. In the last years, survivin is proved to have a significant role in carcinogenesis by crippling the process of apoptosis in the cancer cells, the step which enables the cancer cells to dart the body's immune surveillance mechanisms [7]. 
It is also proved that survivin promotes T-cell proliferation, and differentiation, and hence has a major directory role in the pathogenesis of many autoimmune disorders [8].

Whether survivin has such similar role in the pathogenesis of UC which is still an uncovered interesting issue for research.

Programmed death 1 (PD-1) is a coinhibitory receptor known to be expressed on T cells, B cells, monocytes, and natural killer cells [9].

PD-1 is a member of the B7-CD28 family and has two ligands, PD ligand-1 and -2 (PD-L1 and -L2), both play different roles in the regulation of Th1-Th2 cell function; PD-L1 is proposed to inhibit Th1 responses, while, PD-L2 is suggested to modulate Th2 function [10].

The possible role of PD-1 ligands in UC is another novel area for exploration.

In this study, we examined the immunohistochemical expression of survivin and PD-L1 in UC cases of as step to explore their possible role in UC pathogenesis and progression.

\section{Materials and Methods}

\section{Cases and group}

This study was retrospective study on archived paraffin blocks in the period from 2016 to 2019, from pathology departments in Air Force Specialized Hospital and Nasser Institute for Research and Treatment, Cairo, Egypt, according to the following inclusion criteria:

- $\quad$ Availability of required patient data regarding sex and age.

Availability of the paraffin block with adequate tissue for sectioning.

Cases with a history of prior treatment were excluded from the study.

The study was approved by the ethical committee of Zagazig University (ZU. IRB: 6147-31-1-2019).

The study included 86 cases; 43cases diagnosed as UC and 43 cases of non-specific colitis.

The hematoxylin and eosin stained slides were revised for confirmation of the diagnosis.

Two slides were cut from each block at 3-5 micron for immunohistochemical stains.

\section{The immunohistochemical stains were} performed as following

The immunohistochemical method was performed by an automated immunostainer (Ventana
BenchMark XT; USA) which run the following basic steps: Section deparaffinization with xylene, rehydration with alcohol and then saturation with $0.03 \%$ hydrogen peroxide. This was followed by antigen retrieval with Tris-buffered $0.1 \%$ salineTween-20 at $\mathrm{pH}=7.6$. Incubation was done with the primary antibodies using anti-PD-L1 antibody (M3653 clone 22C3, Dako, Glostrup, Denmark) and survivin Ab 17 antibody (M3624, Clone 12C4. Dako, Carpinteria, CA, USA) at 1:400 dilution for $30 \mathrm{~min}$ at room temperature.

The UltraView Universal DAB Detection Kit was used as the secondary antibody in the device.

Samples were finally counterstained with hematoxylin and mounted in DPX.

\section{Evaluation of immunohistochemical staining}

As monoclonal antibodies to PD-L1 are directed to the extracellular domain of its molecule, so, immunohistochemistry (IHC) staining stains epithelial and immune cells with a mixture of cytoplasmic and membrane staining [11].

The expression of PD-L1 staining in the epithelial cells is estimated and scored from 0 to 3 according to the percentage of positive cells $(0,0 \%$; $1,<25 \% ; 2,25-50 \%$; and $3,>50 \%$ ). Staining intensity was assigned as weak if there was absent or barely identifiable staining at $\times 10$ power, moderate if easily perceptible at $\times 10$ power, and intense if easily seen at $\times 4$ power. Only cases with moderate-to-intense staining intensity were considered positive. Lesions were considered as positive for PD-L1 expression in epithelium when they show at least moderate staining intensity in at least $25 \%$ of cells in at least $50 \%$ of HPs [12].

Evaluation of survivin expression was done semi-quantitatively by grading the intensity of staining ( 0 , absent; 1 , weak; 2 , moderate; and 3 , strong) and determining the percentage of positive cells. The $\mathrm{H}$-score was then obtained by multiplying the percentages of the stained cells by the intensity score of staining. Therefore, the final score values ranged from 0 up to 300 . According to Jakubowska et al., cases were reported as negative when $\mathrm{H}$-score $<150$ and positive when $\mathrm{H}$-score equals or more than 150 [13].

According to Wyss et al.., PD-L1 staining in the stroma (lamina propria) was evaluated subjectively and classified according to the percentage of positive cells within the total area of the lamina propria as: 0: negative, 1: $0.1-1 \%, 2:>1-5 \%, 3:>5-50 \%$, and $4:>50 \%$. PD-L1 positivity in areas of ulceration was not evaluated [14]. Dot-like cytoplasmic staining as well as nuclear staining patterns for PD ligand (PDL)-1 were counted as negative [14]. The expression of survivin in the lamina propria was evaluated using the same scoring system used in PDL1. 
For statistical purposes, the scores of lamina propria positive cells for both markers are subgrouped as low infiltration pattern (including scores 0,1 , and 2) and high infiltration pattern (including scores 3 and 4).

\section{Statistical method}

- Data entry was done using Microsoft Excel 2013 and data analysis was mediated by the Statistical Package for the Social Sciences (SPSS version 24).

- $\quad$ Simple descriptive statistics (arithmetic mean and standard deviation [SD]) used for summary of normal quantitative data and frequencies used for qualitative data.

- $\quad$ Bivariate relationship was displayed in crosstabulations and comparison of proportions was performed using the Chi-square test.

- Independent t-test was used to compare normally distributed quantitative data.

- $\quad$ The level of significance was set at $p<0.05$.

\section{Results}

The study included 86 cases; of them, 43 cases of UC and 43 cases of non-specific (non-IBD) colitis as a comparative control group.

\section{Epidemiological findings}

\section{Gender distribution}

(Figure 1) The study population were 50 males and 36 females.

In the UC group cases, 30 were male $(69.8 \%)$ and 13 were female $(30.2 \%)$. The non-specific colitis cases included 20 males (46.5\%) and 23 females $(53.5 \%)$. The difference between the two groups is significant $(p=0.029)$.

\section{Age distribution}

The overall age of the cases ranged from 18 up to 67 years with mean 40.36 and median 39.00.

Within the UC group, the age ranged from 21 years up to 65 years; with mean $41.23 \pm$ SD 11.497 .

In the non-specific colitis group, the age ranged from 18 years to 67 years, with mean $39.49 \pm$ SD 11.895.

The difference between the two groups was statistically insignificant $(p=0.491)$.

\section{Immunohistochemical results}

Results are shown in Table 1 and Figure 1.

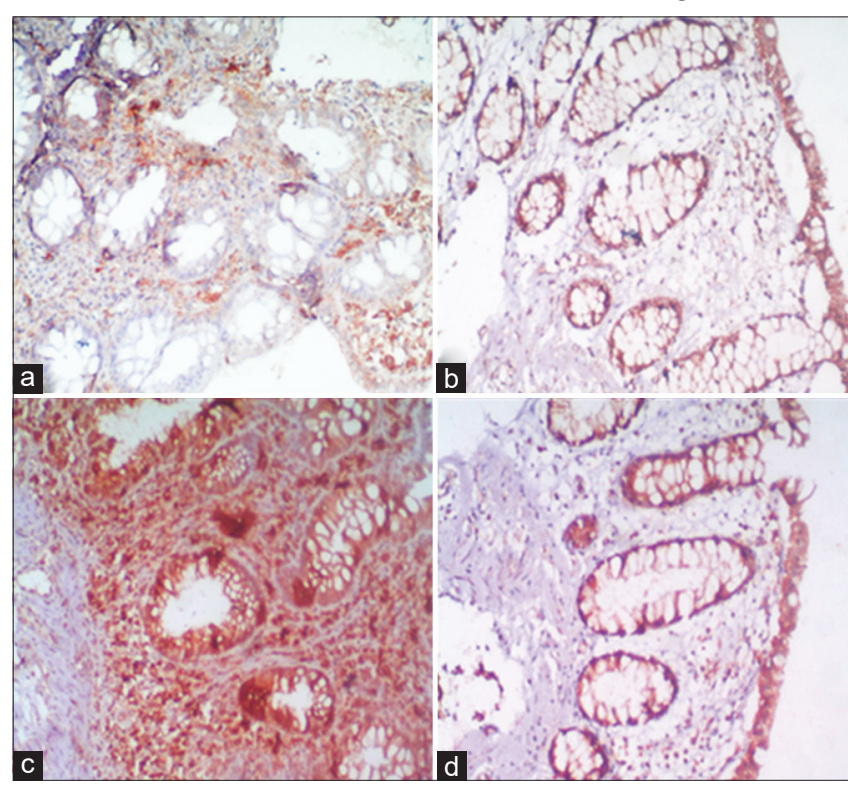

Figure 1: Immunoexpression of both markers in the two diagnostic groups; a: Programmed death ligand (PDLI) expression in ulcerative colitis (UC) cases showed loss of membranous and cytoplasmic expression in the colonic gland cells. The lamina propria showed increased infiltration by the PDL1-positive cells (PDL1 ×200). $b$ : PDL1 expression in a case of non-specific colitis showing constant expression in the colonic gland epithelial cells with few cells in the stroma positive to it $(P D L 1 \times 200)$. C: Survivin expression in a case of UC showing expression in the cells of the colonic glands and marked lamina propria infiltration by survivin-positive cells (survivin $\times 200$ ). $D$ : Survivin expression in a case of non-specific colitis showing diffuse strong expression in the colonic gland cells with few positive cells in the lamina propria (survivin $\times 200$ ) of survivin

\section{Results of immunohistochemical expression}

Survivin expression in the colonic epithelial cells was seen in total 70 of the studied cases $(81.4 \%)$; 33 cases of UC and 37 cases of non IBD colitis, with no statistical difference between the two groups $(p=$ 0.268).

Regarding the lamina propria, the infiltration of survivin positive cells was high in all the cases of UC $(100 \%)$ and low in all cases of non-specific colitis $(p<0.001)$.

\section{Results of immunohistochemical expression} of PDL1

In the epithelial cells of colonic mucosa, PDL1 was positive in 50 cases of the studied population.

UC cases showed positive expression for PDL1 in 12 of them (27.9\%) compared to 31 negative cases $(72.1 \%)$. 
Within non-IBD colitis cases, 38 cases were positive (88.4\%) and 5 cases were negative (11.6\%). The difference between the two studied groups was significant $(p<0.001)$.

Counting the PDL1-positive cells in the lamina propria in the studied cases showed high infiltration rate in $35 \%$ of the UC cases and $0 \%$ of non-specific colitis cases $(p<0.001)$.

Table 1: Comparative results between the two study groups

\begin{tabular}{|c|c|c|c|}
\hline & \multicolumn{2}{|l|}{ Group } & \multirow[t]{3}{*}{$p$ value } \\
\hline & Ulcerative colitis cases & Non-specific colitis cases & \\
\hline & Count (5) & Count & \\
\hline \multicolumn{4}{|l|}{ PDL1 epi } \\
\hline Negative & $31(72.1)$ & $5(11.6)$ & \multirow[t]{2}{*}{${ }^{*}<0.001$} \\
\hline Positive & $12(27.9)$ & $38(88.4)$ & \\
\hline \multicolumn{4}{|l|}{ PDL1 LP } \\
\hline Low infiltrate & $8(18.6)$ & $43(100)$ & \multirow[t]{2}{*}{${ }^{*}<0.001$} \\
\hline High infiltrate & $35(81.4)$ & $0(0)$ & \\
\hline \multicolumn{4}{|l|}{ Surv epi } \\
\hline Negative & $10(23.3)$ & $6(14)$ & \multirow[t]{2}{*}{0.268} \\
\hline Positive & $33(76.7)$ & $37(86)$ & \\
\hline \multicolumn{4}{|l|}{ Surv LP } \\
\hline Low infiltrate & $0(0)$ & $43(100)$ & \multirow[t]{2}{*}{$*<0.001$} \\
\hline High infiltrate & $43(100)$ & $0(0)$ & \\
\hline
\end{tabular}

PDL1 epi... Expression of PDL1 in epithelial colonic cells, PDL1 LP: Infiltration of the lamina propria by PDL (the lamin propria by survivin-positive cells. *: Statistical significance.

\section{Discussion}

UC is a chronic remitting relapsing disease that is characterized by diffuse mucosal epithelial damage and ulceration with ultimate persistent increase inflammatory cell infiltrate [1].

The pathogenesis of UC is not clear until now. The role of different inflammatory mediators and cells, their persistent activation triggers, and their interaction with the mucosa is still a dynamic area for research [5].

In this study, we proposed that survivin and PDL-1 may play a significant role in UC pathogenesis. The study included 43 retrospective cases of UC and 43 cases of non-specific colitis from two centers. The expression of PDL1 and survivin both in the lamina propria and the colonic glands' epithelial cells in both groups was examined using IHC technique.

The studied cases showed a male-to-female ratio near to 7: 3 in the UC group and 1:1 in the non-specific colitis group, with statistically significant difference $(p=0.029)$. Although the number of the included cases in this study is not satisfactory to conclude such gender association, this result was somewhat in concordance to the results of Saha et al. who noticed a significant male higher incidence of UC. However, they restricted this to cases above the age of 45 years [15].

According to our results, survivin expression in the colonic glandular cells showed no statistical difference between the two groups ( $p=0.268)$, while a significant upregulation of lamina propria positive cells between both groups was obtained $(p<0.001)$.
The high density of survivin-positive cells in the lamina propria in UC cases may be then attributed to the its important role as an apoptosis inhibitor and may explain that the autoreactive T cells in UC patient do not undergo apoptosis and hence can sustain a state of continuous chronic inflammation seen in such disorder [16].

Some studies have examined the status of survivin in UC, Rapti et al. examined the levels of survivin expression in UC patients using real-time reverse transcriptase-polymerase chain reaction (PCR) on blood samples and fresh tissue biopsies in their casecontrol study. They concluded that high level of survivin expression was associated with the accumulation of $\mathrm{T}$ cells and cessation of apoptosis in them [17].

In similar regards, Feng et al. have highlighted the possible role of survivin in accumulation of $\mathrm{T}$ cells in the lamina propria in UC patients through the interference of their apoptosis. In their study, they collected samples from peripheral blood of UC patients and healthy subjects and examined the apoptotic status in T cells using the flow cytometry technique [18].

The appealing features of survivin were comprehensively discussed by Pahlavan et al. who introduced survivin as a strong potential biomarker and important player in the pathogenesis of different autoimmune disorders and auto-inflammatory conditions, through its ability to hinder the apoptotic machine in many different pathways [19].

Regarding PDL1 expression, we agreed with other authors who pointed to that the $\mathrm{IHC}$ interpretation of this marker was hard and relatively complicated in many aspects, including the rarity of comparable studies discussing its expression in non-tumorous diseases, as well as the multiplicity of the antibody clones and the nature of the protein being a biological gradient from totally absent, to low, to intermediate, to high that lead to wide staining heterogenicity and interpretation difficulty $[20,21]$.

In our cases, evaluation of PDL1 expression showed a significant raise in the lamina propria positive cells between the UC cases versus the non-specific (non-IBD colitis) $(p<0.001)$. On the other hand, a strong significant loss of PDL1 expression was noticed in cases of UC group when compared with non-specific colitis cases $(p<0.001)$.

The spiked increase of PDL1-positive cells in the lamina propria cases was documented in few previous studies, some of which had also studied the nature of these cells.

Mezache et al. have appreciated the high density of PDL1-positive lamina propria cells in cases UC and suggested that the nature of these cells was mainly CD8 + T lymphocytes [9].

Brusa et al. pointed to the fact that PDL1 will be highly expressed in actively proliferating $T$ and $B$ 
lymphocytes [22], the fact that may explain the high expression of it in the lamina propria of UC cases as a persistently immunologically activated media destroying the colonic glands epithelial layer [23].

In similar regards, Beswick et al. have concluded that PDL1 expression is upregulated in both the intestinal epithelial cells and many cells in the lamina propria. They detailed the nature of these positive cells to include B lymphocytes, macrophages, and myofibroblasts [24]. Nevertheless, they found that the proposed role of PDL1 is still under investigation and that the few published data in this regard are still contradictory [24].

Using the modality of quantitative real-time PCR, Rajabian et al. studied the proposed role of PDL1 in the pathogenesis of UC by measuring the level of gene expression in such cases. They suggested that PDL1 and 2 may act as an important regulator of the immune response in UC; however; they recommended further extensive studies for better understanding of their exact role and the possible benefits from these data in generating related therapeutic options [5].

Based on the fact that normal body cells express PD-L1 protein in order to avoid the damage by T cells, which detect body cells' transmembrane PDL1 by their surface PD1 receptors, leading to immune response downregulation and $\mathrm{T}$ cells apoptosis [21]. Thus, the possible explanation of altered PDL1 expression in UC; in the way that prevent the PDL1/ PD1 interaction and therefore prevent the loop of $\mathrm{T}$ cell inactivation and their apoptosis, the step which may explain the accumulation of $\mathrm{T}$ cell in the lamina propria of UC cases and their persistent activation. In similar fashion, this will explain the accumulation of $T$ cell in the lamina propria of UC cases.

The loss of PDL1 expression in colonic glands mucosal cells in UC is also supported by the incidence of the newly recognized UC like colitis which was reported as a common side effect of PDL1 inhibitors drugs, possibly by similar mechanism of pathogenesis, however, clear understanding of this type of colitis is not yet provided $[25,26]$.

\section{Conclusion}

We pointed to that both PDL1 and survivin may have roles in the pathogenesis of $U C$, we, therefore, recommend further studies to explore their detailed mechanism of action and pathway effectors which may, in turn, suggest novel related treatment modalities for UC.

\section{References}

1. Akpinar MY, Ozin YO, Kaplan M, Ates I, Kalkan IH, Kilic ZM. Platelet-to-lymphocyte ratio and neutrophil-to-lymphocyte ratio predict mucosal disease severity in ulcerative colitis. J Med Biochem. 2018;37(2):155-62. https://doi.org/10.1515/ jomb-2017-0050

PMid:30581352

2. Bing $X$, Linlang L, Keyan C. Decreased Breg/Th17 ratio improved the prognosis of patients with ulcerative colitis. Can J Gastroenterol Hepatol. 2018;2018:5760849. https://doi. org/10.1155/2018/5760849

PMid:29765931

3. Feng $\mathrm{W}$, Yong $\mathrm{H}$, Fengshi D, John HK. Ulcerative colitisassociated long noncoding RNA, BC012900, regulates intestinal epithelial cell apoptosis. Inflamm Bowel Dis. 2016;22(4):782-95. https://doi.org/10.1097/mib.0000000000000691 PMid:26937624

4. Zhang S, Wang S, Miao C. Influence of microbiota on intestinal immune system in ulcerative colitis and its intervention. Front Immunol. 2017;8:1674. https://doi.org/10.3389/fimmu.2017.01674 PMid:29234327

5. Rajabian Z, Kalani F, Taghiloo S, Tehrani M, Rafiei A, HosseiniKhah Z, et al. Over-expression of immunosuppressive molecules, PD-L1 and PD-L2, in ulcerative colitis patients. Iran J Immunol. 2019;16(1):62-70.

PMid:30864556

6. Mikami T, Yoshida T, Akino F, Motoori T, Yajima M, Okayasu I. Apoptosis regulation differs between ulcerative colitis-associated and sporadic colonic tumors. Association with survivin and bcl-2. Am J Clin Pathol. 2003;119(5):723-30. https://doi.org/10.1309/ ylx4l4h36k54x92h PMid:12760292

7. Unruhe B, Schröder E, Wünsch D, Knauer SK. An old flame never dies: Survivin in cancer and cellular senescence. Gerontology. 2016;62(2):173-81. https://doi.org/10.1159/000432398 PMid:26159786

8. Gravina C, Wasén C, Garcia-Bonete MJ, Turkkila M, Erlandsson MC, Silfverswärd ST, et al. Survivin in autoimmune diseases. Autoimmun Rev. 2017;16(8):845-55. https://doi. org/10.1016/j.autrev.2017.05.016 PMid:28564620

9. Mezache L, Magro C, Hofmeister C, Pichiorri F, Sborov D, Nuovo G. Modulation of PD-L1 and CD8 activity in idiopathic and infectious chronic inflammatory conditions. Appl Immunohistochem Mol Morphol. 2017;25(2):100-9. https://doi. org/10.1097/pai.0000000000000298

PMid:27438510

10. Droeser RA, Hirt C, Viehl CT, Frey DM, Nebiker C, Huber X, et al. Clinical impact of programmed cell death ligand 1 expression in colorectal cancer. Eur J Cancer. 2013;49(9):2233-42. https:// doi.org/10.1016/j.ejca.2013.02.015

PMid:23478000

11. Ilie M, Hofman V, Dietel M, Soria J, Hofman P. Assessment of the PD-L1 status by immunohistochemistry: Challenges and perspectives for therapeutic strategies in lung cancer patients. Virchows Arch. 2016;468(5):511-25. https://doi.org/10.1007/ s00428-016-1910-4

PMid:26915032

12. Acosta-Gonzalez G, Ouseph M, Lombardo K, Lu S, Glickman J Resnick MB. Immune environment in serrated lesions of the colon: Intraepithelial lymphocyte density, PD-1, and PD-L1 expression correlate with serrated neoplasia pathway progression. Hum Pathol. 2019;83:115-23. https://doi. 
org/10.1016/j.humpath.2018.08.020

PMid:30172913

13. Jakubowska K, Pryczynicz A, Piekarska VD, Famulski W, Ustymowicz KG. Immunohistochemical expression and serum level of survivin protein in colorectal cancer patients. Oncol Lett. 2016;12(5):3591-7. https://doi.org/10.3892/ol.2016.5075 PMid:27900041

14. Wyss J, Dislich B, Koelzer VH, Galván JA, Dawson H, Hädrich M, et al. Stromal PD-1/PD-L1 expression predicts outcome in colon cancer patients. Clin Colorectal Cancer. 2019;18(1):e20-38. https://doi.org/10.1016/j.clcc.2018.09.007

PMid:30389315

15. Shah SC, Khalili H, Gower-Rousseau C, Olen O, Benchimol EI, Lynge $\mathrm{E}$, et al. Sex-based differences in incidence of inflammatory bowel diseases-pooled analysis of population-based studies from western countries. Gastroentrol. 2018;155(4):1079-89. https://doi.org/10.1053/j.gastro.2018.09.014

PMid:29958857

16. Ebrahimiyan H, Aslani S, Rezaei N, Jamshidi A, Mahmoudi M. Survivin and autoimmunity; the ins and outs. Immunol Lett. 2018;193:14-24. https://doi.org/10.1016/j.imlet.2017.11.004 PMid:29155234

17. Rapti E, Gazouli M, Legaki E, Karamanolis G, Thomas D, Marinos E, et al. Association of survivin promoter polymorphisms with inflammatory bowel disease and response to antitumor necrosis factor therapy. Genet Test Mol Biomarkers. 2015;19(6):339-43. https://doi.org/10.1089/gtmb.2015.0036 PMid:25918954

18. Feng BS, Ma N, Zhang YY, Gao H, Zhang C, Li G, et al. Survivin impairs the apoptotic machinery in cd4 $+t$ cells of patients with ulcerative colitis. J Innate Immun. 2020;12(3):226-34. https:// doi.org/10.1159/000500546

PMid:31330513

19. Pahlavan $\mathrm{Y}$, Kahroba H, Samadi N, Karimi A, Ansarin K, Khabbazi A. Survivin modulatory role in autoimmune and autoinflammatory diseases. J Cell Physiol.
2019;234(11):19440-50. https://doi.org/10.1002/jcp.28725 PMid:31020660

20. Kerr KM, Hirsch FR. Programmed death ligand-1 immunohistochemistry: Friend or foe? Arch Pathol Lab Med. 2016;140(4):326-31. PMid:26756647

21. Liu C, Ghayourilan M, Brown S. Immunohistochemistry and special stains in gastrointestinal pathology practice. Diagn Histopathol. 2020;26(1):22-3.

22. Brusa D, Serra S, Coscia M, Rossi D, D'Arena G, Laurenti L, et al. The PD-1/PD-L1 axis contributes to T-cell dysfunction in chronic lymphocytic leukemia. Haematologica. 2013;98:953-63. https://doi.org/10.3324/haematol.2012.077537 PMid:23300177

23. Tsuda S, Carreras J, Kikuti YY, Nakae H, Dekiden-Monma M, Tsuruya JI, et al. Prediction of steroid demand in the treatment of patients with ulcerative colitis by immunohistochemical analysis of the mucosal microenvironment and immune checkpoint: Role of macrophages and regulatory markers in disease severity. Pathol Int. 2019;69:260-71. https://doi.org/10.1111/pin.12794

24. Beswick EJ, Grim C, Singh A, Aguirre JE, Tafoya M, Qiu S, et al. Expression of programmed death-ligand 1 by human colonic CD90+ stromal cells differs between ulcerative colitis and Crohn's disease and determines their capacity to suppress Th1 cells. Front Immunol. 2018;9:1125. https://doi.org/10.3389/ fimmu.2018.01125

PMid:29910803

25. Assarzadegan N, Montgomery E, Anders RA. Immune checkpoint inhibitor colitis: The flip side of the wonder drugs. Virchows Arch. 2018;472(1):125-33. https://doi.org/10.1007/ s00428-017-2267-z

PMid:29143108

26. Su $Q$, Zhang $X$, Shen $X$, Hou $Y$, Sun $Z$, Gao ZH. Risk of immune-related colitis with PD-1/PD-L1 inhibitors vs chemotherapy in solid tumors: Systems assessment. J Cancer. 2018;9(9):1614-22. https://doi.org/10.7150/jca.24200 PMid:29760800 